\title{
Health-related outcomes of new grocery store interventions: a systematic review
}

\author{
AM Hasanthi Abeykoon ${ }^{1}$, Rachel Engler-Stringer ${ }^{1,2}$ and Nazeem Muhajarine ${ }^{1,2, *}$ \\ 'Department of Community Health and Epidemiology, College of Medicine, Health Sciences Building, University of \\ Saskatchewan, 107 Wiggins Road, Saskatoon, SK, Canada, S7N 5E5: ${ }^{2}$ Saskatchewan Population Health and \\ Evaluation Research Unit, Health Sciences Building, University of Saskatchewan, Saskatoon, SK, Canada, S7N 5 E5
}

Submitted 14 August 2016: Final revision received 20 March 2017: Accepted 12 April 2017: First published online 1 June 2017

\begin{abstract}
Objective: To assess the evidence of the impact of new food store (supermarket/ grocery store) interventions on selected health-related outcomes.

Design: A systematic review following the Effective Public Health Practice Project guidelines. All quantitative studies were assessed for their methodological quality. Results were synthesized narratively.

Setting: Eight electronic databases - MEDLINE, EMBASE, CINAHL, ProQuest Public Health, Web of Science, Scopus, PsycINFO and Cochrane Library - were searched to identify relevant records.

Subjects: Peer-reviewed scholarly journal articles on new grocery store/supermarket interventions with adult study populations, published in the English language after 1995.

Results: Eleven records representing seven new grocery store interventions were identified. Six were assessed having 'weak' methodological quality, one as 'moderate' and two as 'strong'. All studies reported fruit and vegetable consumption but results were not consistent, some studies reporting significantly more and others no increase in consumption. BMI and self-rated health did not show significant improvements. Perceptions of food access, neighbourhood satisfaction and psychological health showed significant improvements.

Conclusions: Improved food access through establishment of a full-service food retailer, by itself, does not show strong evidence towards enhancing health-related outcomes over short durations. Presently the field is developing and the complex linking pathways/mechanisms are yet to be elucidated. Further evidence, in the form of high-quality research in different communities with longer follow-up periods, is needed to inform policy decisions.
\end{abstract}

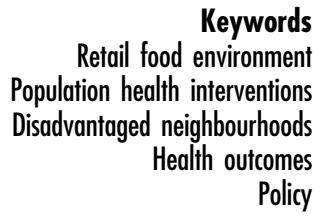

Policy
The presence of supermarkets/grocery stores $\dagger$ in a neighbourhood is associated with buying and consuming healthier food ${ }^{(1)}$. Grocery stores typically sell healthier food items at affordable prices compared with convenience stores and fast-food outlets ${ }^{(2,3)}$. Wide ranges of fresh food choices, with relatively lower price points, frequent availability and visually appealing presentation, are associated with choosing healthier food options and healthier diets ${ }^{(4)}$.

Healthy food access at the neighbourhood level is unequal. This is believed to play a role in the increased prevalence of chronic diseases ${ }^{(5-7)}$. These inequalities

† According to the North American Industry Classification System (NAICS), supermarkets and grocery stores are those that are "primarily engaged in retailing a general line of food, such as canned, dry, and frozen foods; fresh fruits and vegetables; fresh and prepared meats; fish, poultry, dairy products, baked products, and snack foods... ${ }^{, 56)}$. Hereafter the term 'grocery store' is used in the present systematic review to refer to both store types. stratified by income, race, ethnicity and urbanization of neighbourhoods, which have been reported from developed nations in particular ${ }^{(6,8-11)}$, are significant and pose a population health equity concern ${ }^{(6)}$. Food deserts deprived urban regions with limited food access - are a barrier to a healthy diet and contribute to unhealthy eating patterns and related poor health outcomes ${ }^{(12)}$. Although some recent studies show mixed results ${ }^{(13,14)}$, it has been reported that poor healthy food access also influences residents' diets in many ways ${ }^{(15)}$. Mothers with children were mostly constrained by economic access while physical access was the main barrier for the elderly ${ }^{(15)}$. These barriers ultimately contribute to food insecurity where the quality and/or quantity of food consumed are affected ${ }^{(16)}$.

Many major grocery stores have moved away from inner-city low-income neighbourhoods, leaving these neighbourhoods to be served by convenience stores and 
fast-food restaurants or grocery stores situated a significant distance away ${ }^{(17)}$. While spatial food access disparities are explicitly seen as a threat to public health, social exclusion that results from socio-economic and cultural segregation should not be underestimated ${ }^{(16,18)}$. Low-income disadvantaged neighbourhoods are the most affected when it comes to poor grocery store access ${ }^{(16,19)}$. In some cases, however, these communities have physical and economic access to fast-food outlets, where foods high in fat, sugar and salt, that are minimally nutritious, are sold ${ }^{(6)}$.

Eating behaviour is complex and is shaped by many factors such as policy, environmental and individual variables ${ }^{(20)}$. While disparities in these factors leading to health inequities have been widely identified, attempts are being made to find the most effective ways to address them. Guided by an ecological framework, the most successful levels at which to intervene have been recognized as environmental and policy levels ${ }^{(21)}$. One such effort to improve healthy food access is the development of grocery stores in areas with poor access. Due to the complex nature of these interventions, involving many parties, successful examples of such operations are few in number or small in scope.

The present systematic review intends to address the knowledge gap on systematically developed evidence on the effectiveness of newly opened grocery stores. Although there are systematic reviews available on interventions based in small food stores ${ }^{(22)}$ and grocery stores ${ }^{(23)}$, there have been no reviews to our knowledge examining the impact of newly opened grocery stores. The objectives of the review are to systematically synthesize evidence from published peerreviewed literature on the effectiveness of new grocery stores on diet and selected health-related outcomes, and to identify areas that need further research. It is anticipated that these efforts will inform evidence-based public health practice, policy and programmes, and consequently contribute to reduce inequalities in healthy food access. The specific research question to be addressed is 'How do new retail food store (grocery store) interventions influence diet and selected health-related outcomes in adults?

\section{Methods}

The present review followed the steps for conducting systematic reviews summarized by the Effective Public Health Practice Project (EPHPP), which recommended these steps: (i) question formulation; (ii) literature retrieval; (iii) developing relevance criteria; (iv) assessing studies for relevance and then for methodological quality; (v) data extraction and narrative synthesis; (vi) peer review of the report; and (vii) dissemination ${ }^{(24)}$.

\section{Question formulation and establishing relevance criteria}

The research question was developed to represent the adult population, new retail grocery store interventions and the selected health-related outcomes. The research question did not name a specific comparison group, although it was understood that individual studies may have chosen comparison groups. In addition, we anticipated that some studies would have investigated the impact of only newly opened grocery stores, or only within-store interventions, or combination of these two types of interventions. Although the focus of the review was on new grocery store openings, in order to capture those studies with a combination of both intervention types, the research question was framed in broad terms.

Inclusion criteria were: (i) assessing an adult study population; (ii) newly opened retail grocery store or a combination of new store and within-store interventions; (iii) assessment of any of the following health-related outcomes: physical or psychological health, either selfreported or diagnosed by a physician, e.g. obesity (BMI), psychosocial factors, food security, dietary habits (fruit and vegetable (F\&V) consumption, F\&V purchase, food-related behaviour); and (iv) peer-reviewed scholarly articles published in or after 1995 in the English language.

The decision to include adults as the target population was due to children's dietary behaviour and food choices being highly influenced by and dependent on factors including but not limited to parents' food habits and school food programmes. Grocery stores were selected as they sell and promote a greater variety of 'healthy' foods compared with other types of food stores. The objective was to review evidence related to the impact of new grocery store interventions on health-related outcomes. The field of study is relatively new and there is practically no literature published prior to the last two decades. Therefore, the search was limited to studies published on or after 1995.

Exclusion criteria were: (i) having a study population who are only pregnant women, overweight or obese populations, or those with chronic disease conditions; (ii) interventions which focus solely on organizational nutrition environments (e.g. schools, hospitals) or the information environment (e.g. media reports, public or media campaigns); and (iii) studies with specific focus on ready-to-eat/takeaway food outlets such as restaurants or cafeterias.

\section{Literature retrieval and search strategy}

Eight electronic databases were searched: Ovid MEDLINE, EMBASE, Cumulative Index to Nursing and Allied Health Literature (CINAHL), ProQuest Public Health, Web of Science, Scopus, PsycINFO and Cochrane Library. The search strategy, initially developed on MEDLINE (see Table 1), was adapted to the other seven databases (see online supplementary material for comprehensive search strategy). The search strategy was developed for three core concepts: (i) food/nutrition environment (e.g. grocer*, supermarket*, food retail*, etc.); (ii) intervention 
Table 1 Search strategy developed in MEDLINE

\begin{tabular}{|c|c|}
\hline Database & Search strategy \\
\hline MEDLINE & 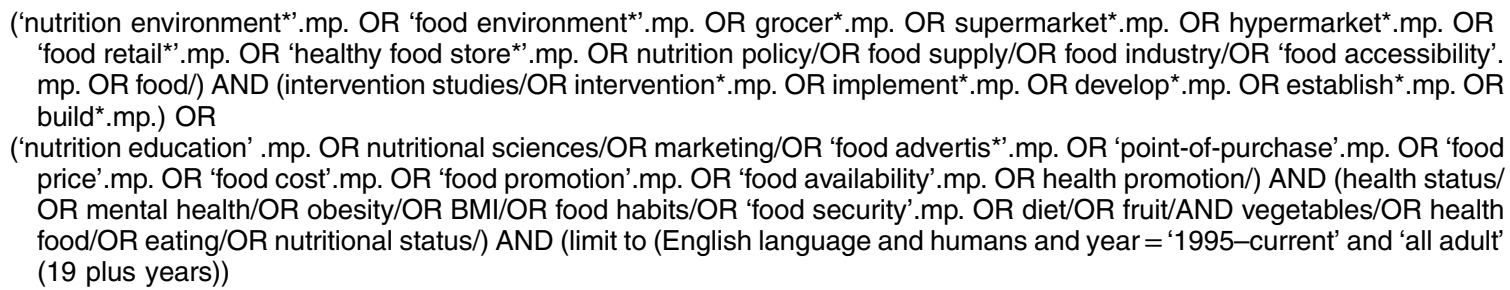 \\
\hline
\end{tabular}

(e.g. implement*, develop*, establish*, etc.); and (iii) healthrelated outcomes (e.g. obesity, BMI, food habits, etc). Once relevant records were identified during the initial search, reference lists of these records were manually searched to identify any further records. All records were imported into one RefWorks folder and duplicates were removed systematically. The electronic search and article retrieval were conducted between 22 and 24 August 2015 and email alerts were requested, when possible, from databases to identify any new publications until November 2015.

Due to the large number of records involved, it was difficult to have two reviewers independently work on the article screening process. Initial title screening was carried out by A.M.H.A., T.R., J.H., M.G. and M.C.* At this point the reviewers were asked to be overly inclusive and only to remove records that were clearly not relevant considering the inclusion and exclusion criteria. Afterwards, abstract screening, full article review for eligibility and a manual search of reference lists of identified records were carried out by A.M.H.A. Records which were not clearly within the exclusion criteria were reviewed by a second reviewer.

\section{Quality assessment and data extraction}

Eligible studies were assessed for their methodological quality using the EPHPP Quality Assessment Instrument for quantitative studies and the accompanying dictionary $^{(25)}$. This standardized tool has been tested and shown to have adequate content and construct validity and acceptable levels of inter-rater reliability ${ }^{(24,26)}$.

Each quantitative study was independently assessed and scored by two raters for quality with respect to selection bias, study design, confounding, blinding, data collection method and rates of withdrawal/dropouts ${ }^{(25)}$. The instrument allocated a global descriptive rating for each study as 'strong', 'moderate' or 'weak' based on the ratings for the above six components ${ }^{(25)}$. If the study did not yield any 'weak' rating for the above six components, it was rated as 'strong'. If there was only one 'weak' component rating, the study was scored as 'moderate' in quality, and if there were two or more 'weak' ratings the

*A.M.H.A. = Hasanthi Abeykoon, T.R. = Tracy Ridalls, J.H. = Joel Heitmar, M.G. = Melissa Gan, M.C. = Mike Chouinard. study was scored as 'weak' (25). Disagreements between the two raters for a particular study were discussed with a third rater.

Regardless of the methodological quality rating, all records were included in the present review for the reasons discussed below. Retail food environment interventions such as new grocery store openings in neighbourhoods with limited healthy food access are relatively under-evaluated natural experiments. As such, manipulating the intervention exposure, in a similar way to randomized controlled trials or other types of planned experiments, is rarely if ever achieved ${ }^{(27)}$. Nevertheless, evidence produced by these natural studies is extremely useful when crucial confounding variables are known and controlled $^{(27,28)}$. The component ratings used in the EPHPP Quality Assessment Instrument focused specifically on components that are barriers that natural experiments typically encounter. Therefore, it would be inappropriate to exclude studies from the review based solely on methodological quality.

Data relevant to the present review were extracted into a data extraction sheet which defined and sorted data along study location, study design, characteristics of intervention and comparison populations, length of follow-up, number of participants in each group and health-related outcomes reported. Afterwards, results were synthesized narratively.

\section{Results}

\section{Selection of studies}

The search of eight databases identified 12972 prospective records. Out of these, 4290 records were systematically removed during de-duplication. The remaining 8682 records initially underwent a title screening and 8583 records, for the purpose of the study, were excluded as they fell clearly outside of the topic of interest. Screening of the full abstract was carried out on the remaining ninety-nine articles; of these, forty-three records were eliminated as they fell outside the topic of interest or inclusion criteria, leaving fifty-six articles for full-text review. Fifty records were excluded during full article review because they did not meet inclusion criteria; 


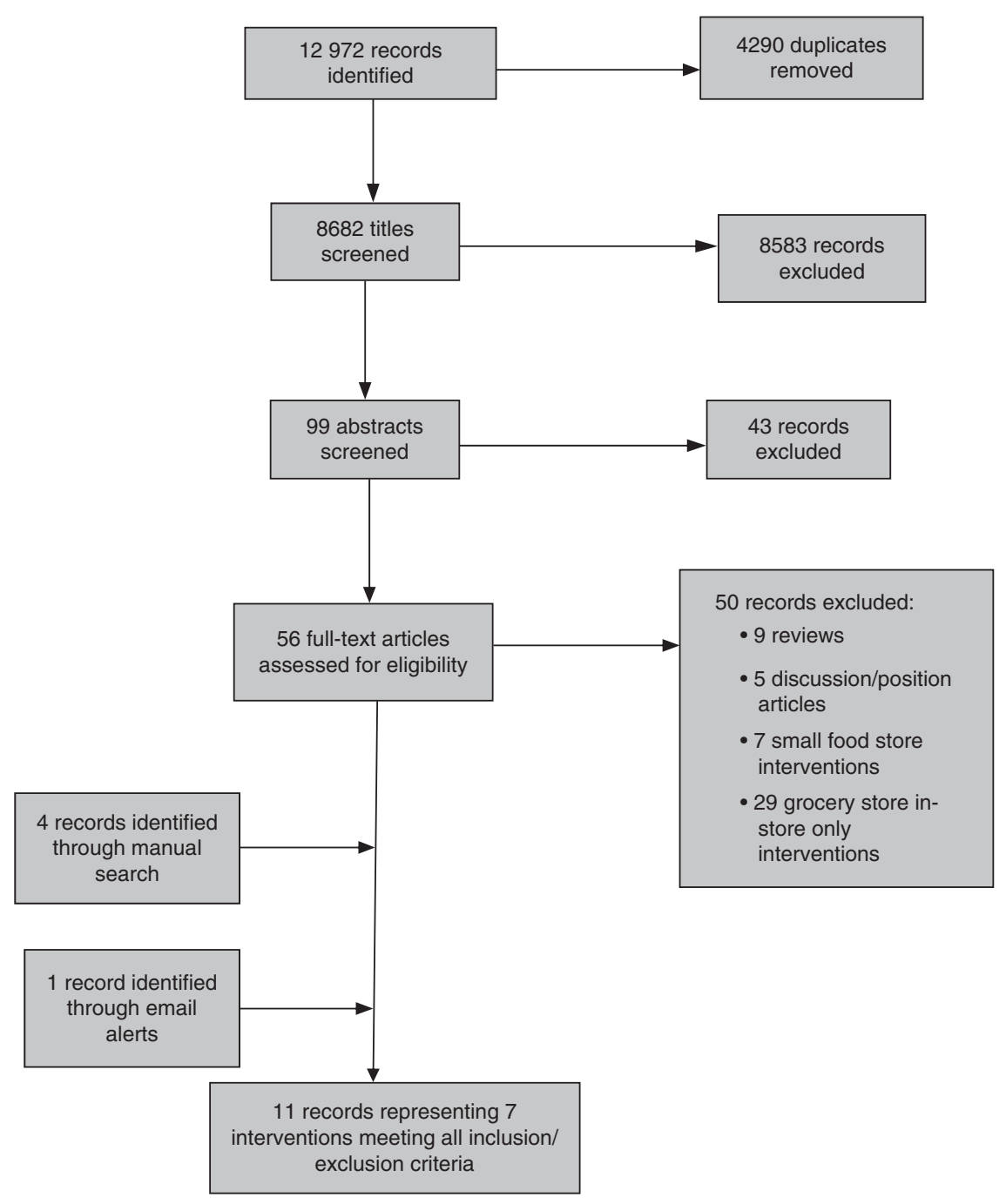

Fig. 1 Flow diagram of the study selection process

specifically, nine were reviews, seven were small food store interventions, five were discussion/position papers and twenty-nine were exclusively on within-store interventions. Six eligible records were retrieved and their reference lists were searched, and this identified four more records. Further, one more record was identified through the email alerts. This resulted in eleven eligible articles representing seven interventions meeting all inclusion criteria, which were then included in the present systematic review. Figure 1 shows the flow diagram of the study selection process.

\section{Quality of included studies}

Nine of the eligible records were quantitative studies and they were subjected to methodological quality assessment ${ }^{(29-37)}$. Of the two records that were not assessed for methodological quality, one comprised a combination of qualitative and quantitative methodology ${ }^{(38)}$, while the other was purely qualitative ${ }^{(39)}$. The quality assessment revealed that the majority of the records (six) were of 'weak' methodological quality (29,30,32-35), while two studies scored 'strong'(36,37) and one study was of 'moderate' methodological quality ${ }^{(31)}$. Table 2 shows the quality assessment results of individual studies.

Among the eleven records, ten included study designs that controlled for known and potential confounders during either the design or analysis phase. Five of the studies had comparison groups that were matched with intervention neighbourhoods for known risk factors such as income, neighbourhood deprivation, education, race/ ethnicity or geographical distance to main healthy food store $^{(30,31,34,36-38)}$. In the case of the Seacroft (Leeds, England) intervention, where one sample was followed up from baseline to after the intervention, Wrigley et al. and Gill and Rudkin explicitly discussed and controlled for known risk factors within participant groups ${ }^{(29,32,35)}$. However, with a one-time survey of residents living close to the intervention store, Wang et al. did not report any adjustments made ${ }^{(33)}$. In the study by Cummins et al., confounders were addressed at multiple stages, such as 
Table 2 Methodological quality rating results showing the six component ratings and global ratings of individual studies

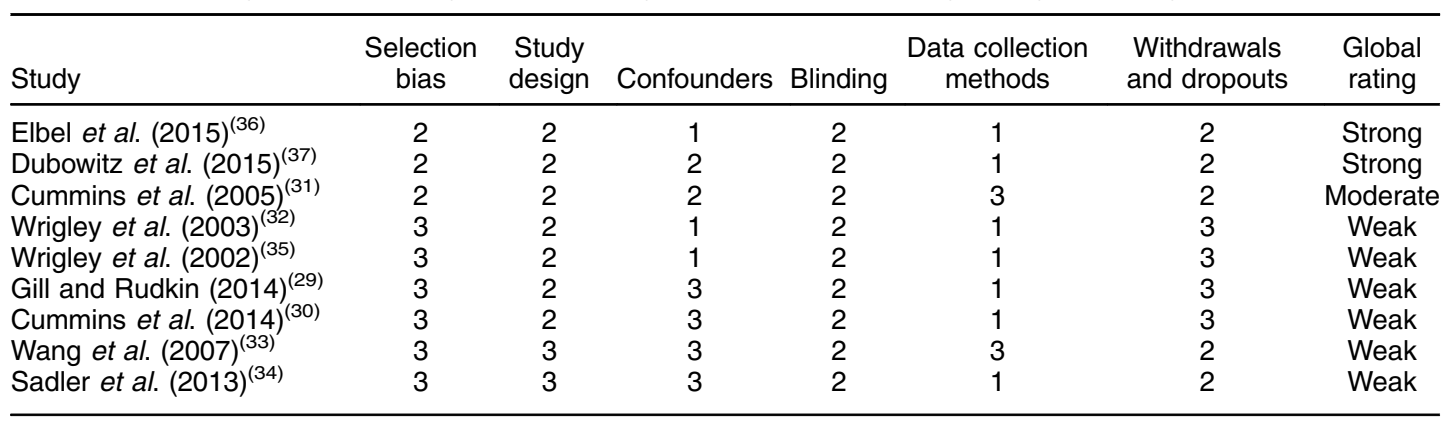

at the design phase by matching and at the analytical phase by selection, and then adjusting for confounders ${ }^{(30)}$. Several factors prevented Sadler et al. from repeating the follow-up on the same sample of study population ${ }^{(34)}$. However, they identified this limitation and took several measures to control the variability that resulted. For example, they asked additional questions about previous shopping behaviour of participants in the second phase and, further, treated them as four different samples in the analysis rather than two samples which were followed up ${ }^{(34)}$.

Studies used either intention-to-treat and/or ontreatment analysis as analytical methods. Intentionto-treat analysis evaluates population/community-level impact by comparing intervention and comparison neighbourhoods, while on-treatment analysis evaluates individual- or subgroup-level impact by comparing participants who adhere to treatment exactly as assigned with those who are not assigned to treatment ${ }^{(40)}$. Among the interventions included in the present review, five had comparison groups ${ }^{(30,31,34,36-38)}$, while two interventions did not ${ }^{(29,32,33,35,39)}$. Among studies with a control group, three had presented both forms of analytical results $^{(30,31,37,38)}$, while Elbel et al. reported intentionto-treat analysis only ${ }^{(36)}$. Wrigley et al.'s study and secondary analysis of data by Gill and Rudkin presented results of switchers $v$. non-switchers ${ }^{(29,32,35)}$, while the other two studies used other methods ${ }^{(33,34)}$.

Statistical power was at least mentioned by five out of nine records ${ }^{(30-32,36,38)}$. Wrigley et al. and Elbel et al. considered statistical power for sample size calculations at the design phase $\mathrm{e}^{(32,36)}$. Some authors suggested that the small number of switchers might have led to the attenuated statistical power ${ }^{(30,31,33,36,38)}$.

\section{Measures used to assess outcomes}

Data collection tools utilized to assess outcomes were different among studies. Six studies included detailed, valid and reliable instruments ${ }^{(30,31,34,36-38)}$. In some other interventions new questionnaires were developed and tested for content, clarity and sensitivity prior to use in the study $^{(33)}$. BMI where evaluated was either based on objectively measured height and weight ${ }^{(37)}$, or self- reported $^{(30)}$. Cummins et al. assessed F\&V consumption using a single question where they inquired how many portions of $F \& V$ participants usually eat per day ${ }^{(31)}$.

\section{Health-related outcomes}

Some of the studies included findings not of interest to the present review; reported below are the outcomes that are within the scope of the review. A summary of study characteristics is given in Table 3 .

\section{Fruit and vegetable consumption}

The most frequently investigated outcome was the impact of the new grocery store on F\&V consumption. This was reported by all studies, and the results are diverse. A recent intervention, where the effect of a governmentsubsidized grocery store was examined, discovered a decline in self-reported F\&V availability in households with children aged 3-10 years in both intervention (from 77 to $68 \%$; significant) and comparison (from 78 to $65 \%$; significant) groups ${ }^{(36)}$. However, salty snack availability in the intervention group was reported to be reduced to $23 \%$ from $32 \%$ (significant) during the first follow-up ${ }^{(36)}$.

A recent grocery store intervention in Pittsburgh, Pennsylvania, USA monitored consumption of different dietary components including $F \& V^{(37)}$. They found that those who lived in the intervention neighbourhood consumed significantly less energy $(-178 \mathrm{kcal} / \mathrm{d}(-745 \mathrm{~kJ} / \mathrm{d}))$, added sugars ( -3.34 teaspoons/d) and calories from solid fats, alcohol and added sugars $(-3 \cdot 11 \%$ of daily energy) compared with the comparison neighbourhood. They measured these outcomes using a difference-indifferences method. The amount of F\&V and wholegrain consumption, however, was also reported to have been reduced (non-significantly) at -0.14 servings/d and -0.05 ounces/d $(-1.4 \mathrm{~g} / \mathrm{d})$, respectively, in the intervention $v$. control groups. As well, all these outcomes were reduced among regular users of the new grocery store compared with others in the intervention group; however, these were not statistically significant ${ }^{(37)}$.

Cummins et al. reported findings from an intervention in a deprived neighbourhood in Glasgow, Scotland, where a new hypermarket was built ${ }^{(31,38)}$. The quantitative research revealed, after adjusting for baseline 
Table 3 Characteristics of selected studies and methodological quality ratings

\begin{tabular}{|c|c|c|c|c|}
\hline Study, location & $\begin{array}{l}\text { Study design, intervention and } \\
\text { control population characteristics }\end{array}$ & $\begin{array}{l}\text { Period of data collection, intervention } \\
\text { and comparison group numbers }\end{array}$ & Relevant outcomes & $\begin{array}{l}\text { Methodological quality } \\
\text { rating, comments }\end{array}$ \\
\hline $\begin{array}{l}\text { Wrigley et al. }(2002)^{(35)} \text { and } \\
\text { Wrigley et al. }(2003)^{(32)} \\
\text { Seacroft, Leeds, } \\
\text { England }\end{array}$ & $\begin{array}{l}\text { A 'before/after' study } \\
\text { Opening a new food store (Tesco Superstore) in } \\
\text { Nov } 2000 \\
\text { A low-income, deprived, white (ethnically } \\
\text { less diverse than the city as a whole) area }\end{array}$ & $\begin{array}{l}\text { - Jun-Jul } 2000 \text { ( } 5 \text { months before) and } \\
2001 \text { ( } 7-8 \text { months after intervention) } \\
\text { - Before, } n 1009 \text {; after, } n 615 \\
\text { - No comparison group }\end{array}$ & $\begin{array}{l}\text { - Mean F\&V consumption increased from } 2.88 \text { to } 2.92 \\
\text { portions/d (NS) } \\
\text { F } F V \text { consumption increased significantly among those } \\
\text { who had poor (by } 0.44 \text { portions/d) and worst } \\
\text { (by } 0.82 \text { portions/d) diets pre-intervention } \\
\text {. F\& } V \text { consumption of switchers increased significantly } \\
\text { by } 0.23 \text { portions/d }\end{array}$ & $\begin{array}{l}\text { - Weak quality (both } \\
\text { articles) } \\
\text { - Most of the important } \\
\text { confounders were } \\
\text { included in the analysis }\end{array}$ \\
\hline $\begin{array}{l}\text { Wrigley et al. (2004) } \\
\text { Seacroft, Leeds, } \\
\text { England }\end{array}$ & $\begin{array}{l}\text { - A qualitative focus group study post-intervention } \\
\text { The above same intervention (Wrigley et al. }{ }^{\left({ }^{35}\right)} \\
\text { and Wrigley et al. }{ }^{(32)} \text { ) }\end{array}$ & $\begin{array}{l}\text { - Sep } 2002 \text { ( } 22 \text { months post-intervention) } \\
\text { Eight focus groups (each with up to eight } \\
\text { participants; total } n 49) \\
\text {. Five of them were 'switchers' to the } \\
\text { new store } \\
\text { - Age gradient: } 17-34,35-54,>55 \text { years }\end{array}$ & $\begin{array}{l}\text { - Switching due to convenience, accessibility and sense } \\
\text { of potential saving money } \\
\text { - Temptation to overspend } \\
\text { Self-esteem and alienation created, intimidated by } \\
\text { 'outsider' shoppers } \\
\text { - Negative attitude towards healthy eating among younger } \\
\text { participants, few middle-aged and older participants } \\
\text { improved healthy eating after intervention }\end{array}$ & $\begin{array}{l}\text { - Did not undergo quality } \\
\text { assessment }\end{array}$ \\
\hline $\begin{array}{l}\text { Gill and Rudkin }(2014)^{(29)} \\
\text { Seacroft, Leeds, } \\
\text { England }\end{array}$ & $\begin{array}{l}\text { - Secondary analysis of data from } \\
\text { Wrigley et al's study }\end{array}$ & $\begin{array}{l}599 \text { observations from the second wave } \\
\text { of the Seacroft Intervention Study }\end{array}$ & $\begin{array}{l}\text { F\&V consumption improved among those who lived near } \\
\text { the new store, those who previously consumed more } \\
F \& V \text { and those who choose to use it ('switchers') }\end{array}$ & - Weak quality \\
\hline $\begin{array}{l}\text { Cummins et al. (2014) } \\
\text { Pennsylvania, PA, USA }\end{array}$ & $\begin{array}{l}\text { - Controlled pre-post quasi-experimental } \\
\text { longitudinal study } \\
\text { - Opening a new supermarket }\left(41000 \mathrm{ft}^{2}\left(\sim 3810 \mathrm{~m}^{2}\right)\right) \text { in } \\
\text { Dec 2009, a pilot study } \\
\text { - 'Food desert', low-income, black }\end{array}$ & $\begin{array}{l}\text { - Pre: Jun-Sep } 2006 \\
\text { - Post: Jun-Nov } 2010 \text { ( } 6 \text { months post- } \\
\text { intervention) } \\
\text { - Intervention: pre, } n 723 \text {; post, } n 311 \\
\text { - Comparison: pre, } n \text { 717; post, } n 345\end{array}$ & $\begin{array}{l}\text { No significant difference-in-differences for BMI \& } \\
\text { F\&V intake in the intervention } v \text {. comparison } \\
\text { Adjusted difference-in-differences for perceptions of } \\
\text { food access }=1.47\end{array}$ & $\begin{array}{l}\text { - Weak quality } \\
\text { Matched intervention } \\
\text { and comparison groups }\end{array}$ \\
\hline $\begin{array}{l}\text { Wang et al. (2007) })^{(33)} \\
\text { California, USA }\end{array}$ & $\begin{array}{l}\text { - One-time survey } \\
\text { Opening a full-service grocery store in the neigh- } \\
\text { bourhood centre in mid-2004 } \\
\text { A low socio-economic neighbourhood in a moderate- } \\
\text { sized city; the nearest full-service grocery store was } \\
\text { located }>1 \text { mile }(>1.6 \mathrm{~km} \text { ) away from most residences } \\
\text { (before intervention) }\end{array}$ & $\begin{array}{l}\text { - } 78 \text { adults }(>18 \text { years) who lived within } \\
\text { a } 2 \text {-mile }(3 \cdot 2 \mathrm{~km}) \text { radius of the new } \\
\text { grocery store } \\
6 \text { months after the intervention } \\
\text { - No comparison group }\end{array}$ & $\begin{array}{l}\text { - No increase in F\&V consumption } \\
42 \% \text { who received nutrition education consumed fruit } \\
\geq 2 \text { times/d } v .17 \% \text { who never had nutrition education } \\
\text { (marginal evidence) }\end{array}$ & $\begin{array}{l}\text { - Weak quality } \\
\text { No reported } \\
\text { adjustments for } \\
\text { confounders }\end{array}$ \\
\hline $\begin{array}{l}\text { Sadler et al. }(2013)^{(34)} \\
\text { Flint, MI, USA }\end{array}$ & $\begin{array}{l}\text { - A 'before/after' study } \\
\text { - Opening an independent grocery store (Witherbee's } \\
\text { Market) in Jun } 2010 \text { (and closed Nov 2011) } \\
\text { - Intervention neighbourhood was socio-economically } \\
\text { disadvantaged, with a high proportion of black } \\
\text { residents and was a 'food desert', while comparison } \\
\text { neighbourhood was served by a grocery store }\end{array}$ & $\begin{array}{l}\text { - Pre: Apr-Jun } 2009 \\
\text { Post: Apr-Jun } 2011 \text { (1 year after opening } \\
\text { the grocery store) } \\
\text { Pre, } n 186 \\
\text { - Post, } n 166\end{array}$ & $\begin{array}{l}\text { - Food consumption: no significant differences } \\
\text { between intervention and comparison groups } \\
\text { - Significant increase in prepared food consumption in } \\
\text { intervention group }\end{array}$ & $\begin{array}{l}\text { - Weak quality } \\
\text { Random selection of } \\
\text { participants from the } \\
\text { intervention \& } \\
\text { comparison sites } \\
\text { - } 15 \% \text { response rate }\end{array}$ \\
\hline
\end{tabular}


Table 3 Continued

\begin{tabular}{|c|c|c|c|c|}
\hline Study, location & $\begin{array}{l}\text { Study design, intervention and } \\
\text { control population characteristics }\end{array}$ & $\begin{array}{l}\text { Period of data collection, intervention } \\
\text { and comparison group numbers }\end{array}$ & Relevant outcomes & $\begin{array}{l}\text { Methodological quality } \\
\text { rating, comments }\end{array}$ \\
\hline $\begin{array}{l}\text { Cummins et al. }(2005)^{(31)} \\
\text { and Cummins et al. } \\
(2008)^{(38)} \\
\text { Springburn, Glasgow, } \\
\text { Scotland }\end{array}$ & $\begin{array}{l}\text { - Prospective controlled 'before and after', } \\
\text { a quasi-experimental design and a qualitative } \\
\text { focus group study } \\
\text { - A new Tesco hypermarket opened in Nov } 2001\end{array}$ & $\begin{array}{l}\text { - Pre: Oct } 2001 \\
\text { - Post: Oct } 2002 \text { (follow-up period } \\
10 \text { months) } \\
\text { - Qualitative component = 6-7 months } \\
\text { after opening store } \\
\text { - Intervention: pre, } n \text { 293; post, } n 191 \\
\text { - Comparison: pre, } n \text { 310; post, } n 221\end{array}$ & $\begin{array}{l}\text { - Intervention } v \text {. comparison } \mathrm{F} \& \mathrm{~V} \text { consumption: } \\
-0.10 \text { portions/d }(95 \% \mathrm{Cl}-0.59 \text { to } 0.40) \\
\text { - Mean fruit consumption: } 0.03 \text { portions/d } \\
(95 \% \mathrm{Cl}-0.25 \text { to } 0.30) \\
\text { - Mean vegetable consumption: }-0.11 \text { portions/d } \\
(95 \% \mathrm{Cl}-0.44,0.22) \\
\text { - Fair-to-poor health: adjusted } \mathrm{OR} \text { increase } \\
\text { in the intervention } v \text {. comparison, } 1.52(95 \% \mathrm{Cl} 0.77, \\
2.99), \mathrm{NS} \\
\text { - Poor psychological health: adjusted OR reduction in the } \\
\text { intervention } v \text { comparison, } 0.57 \text { ( } 95 \% \mathrm{Cl} 0.29,1 \cdot 11), \mathrm{NS} \\
\text { Qualitative study: increased variety \& availability, no } \\
\text { report of change in diet due to new store, improve social } \\
\text { inclusion and employment }\end{array}$ & $\begin{array}{l}\text { - Moderate quality } \\
\text { (Cummins et all(13)) } \\
\text { - Random sampling } \\
\text { of households } \\
\text { - Control for confounders } \\
\text { at design (matching by } \\
\text { the level of deprivation) } \\
\text { and analysis phases } \\
\end{array}$ \\
\hline $\begin{array}{l}\text { Elbel et al. }(2015)^{(36)} \\
\text { Morrisania, South Bronx, } \\
\text { New York City, USA }\end{array}$ & $\begin{array}{l}\text { - Difference-in-difference study design } \\
\text { - A new supermarket opening }\left(17000 \mathrm{ft}^{2}\left(\sim 1580 \mathrm{~m}^{2}\right)\right) \\
\text { in Aug } 2011 \\
\text { - Largely African-American or Hispanic/ } \\
\text { Latino, low-income neighbourhoods with } \\
\text { comparatively low grocery store area } \\
\text { availability per person } \\
\text { - 'Supermarket high need areas' }\end{array}$ & $\begin{array}{l}\text { - Baseline: Mar-Aug } 2011 \\
\text { - Second round: Sep-Dec } 2011 \\
\text { - Third round: Aug } 2012 \text { (1 year } \\
\text { after the supermarket opened) } \\
\text { - Intervention: pre, } n \text { 412; post1, } \\
\quad n 421 \text {; post2, } n \text { 239 } \\
\text { - Comparison: pre, } n \text { 423; post1, } \\
n \text { 407; post2, } n 270\end{array}$ & $\begin{array}{l}\text { - Household F\&V availability declined in both groups } \\
\text { during post2 from } 77 \text { to } 68 \% \text { in intervention and } \\
\text { from } 78 \text { to } 65 \% \text { in comparison } \\
\text { - Household availability of salty snacks decreased in } \\
\text { intervention at post1, from } 32 \text { to } 23 \% \text {. At post2, NS }\end{array}$ & $\begin{array}{l}\text { - Strong quality } \\
\text { - Matched intervention \& } \\
\text { comparison groups } \\
\text { - Participants are not } \\
\text { aware of the } \\
\text { intervention }\end{array}$ \\
\hline $\begin{array}{l}\text { Dubowitz et al. (2014) })^{(37)} \\
\text { Pittsburgh, PA, USA }\end{array}$ & $\begin{array}{l}\text { - Quasi-experimental longitudinal design } \\
\text { - A Healthy Food Financing Initiative-funded } \\
\text { full-service supermarket opened in Oct } 2013 \\
\text { - Socio-economically and geographically matched } \\
\text { intervention and comparison neighbourhoods } \\
\text { - African-American, low-income food desert } \\
\text { at baseline }\end{array}$ & $\begin{array}{l}\text { - Baseline: May-Dec } 2011 \\
\text { - Follow-up: May-Dec } 2014 \\
\text { - Intervention: } n 571 \\
\text { - Comparison: } n 260\end{array}$ & $\begin{array}{l}\text { - Significant difference-in-differences between the } \\
\text { intervention } v \text {. comparison in mean daily energy } \\
\text { intake }=-178 \mathrm{kcal}(-745 \mathrm{~kJ}) \text {, added sugars in } \\
\text { teaspoons }=-3 \cdot 34 \text {, solid fats, alcohol and added } \\
\text { sugars }=-3 \cdot 11 \text { of energy, neighbourhood } \\
\text { satisfaction }=11 \cdot 10 \% \text { and all the components of } \\
\text { perceived access to healthy food } \\
\text { - No significant changes in F\&V intake or average BMI } \\
\text { between the intervention } v \text {. comparison } \\
\text { - No significant changes in components of diet, } \\
\text { neighbourhood satisfaction or average BMl between } \\
\text { regular shoppers } v \text {. others in intervention group } \\
\text { - Perceived access to health food was significantly } \\
\text { increased in regular users }\end{array}$ & $\begin{array}{l}\text { - Strong quality } \\
\text { Random sampling } \\
\text { - } 87 \% \text { of eligible } \\
\text { participated } \\
\text {. Control of confounders } \\
\text { during design } \\
\text { (mathing) and } \\
\text { analyses }\end{array}$ \\
\hline
\end{tabular}

$\mathrm{F} \& \mathrm{~V}$, fruit and vegetables. 
consumption and other relevant confounders, a statistically borderline increase of fruit consumption ( 0.03 portions $/ \mathrm{d} ; 95 \% \mathrm{CI}-0 \cdot 25,0 \cdot 30)$ and a small (negative) impact on vegetable $(-0.11$ portions $/ \mathrm{d} ; 95 \% \mathrm{CI}-0.44,0.22)$ and F\&V consumption $(-0.10$ portions/d; $95 \% \mathrm{CI}-0.59,0.40)$ in the intervention compared with comparison neighbourhoods ${ }^{(31,38)}$. Separate analyses of 'switchers' (study participants who had a different primary grocery store at the study start and who said that the new store was their primary grocery store during the follow-up) compared with 'non-switchers' showed a slight increase (but not statistically significant) in all the above three consumption levels ${ }^{(31,38)}$

Another study, also by Cummins et al. and examining the impact of a supermarket built in Philadelphia, Pennsylvania, USA, reported in unadjusted intention-totreat or adopters $v$. non-adopters analyses that there were no significant difference-in-differences in the F\&V consumption ${ }^{(30)}$. As well, an intervention in the USA (Flint, Michigan) failed to detect any improvements in healthy eating behaviour; in fact, they detected that the postintervention group was significantly more likely to either eat out in restaurants or purchase prepared (usually less healthy) meals from the new store, than during the pre-intervention period ${ }^{(34)}$. Similarly, no significant associations with food consumption behaviour were identified by Wang et al. due to a new grocery store in California, USA ${ }^{(33)}$.

Research on the impact of a new superstore in Seacroft, Leeds, provided four out of the eleven studies included in the present review ${ }^{(29,32,35,39)}$. The initial analyses by Wrigley et al. revealed a slight increase (but not significant) in F\&V consumption from 2.88 to 2.92 portions/ $\mathrm{d}^{(32,35)}$. Respondents with poor $(\leq 2$ portions/d) and the worst $(<1$ portion/d) pre-intervention diets improved by 0.44 and 0.83 portions/d during post-intervention, respectively. Further, analyses into switchers showed a significant 0.23 portions/d rise in F\&V consumption. As well, Gill and Rudkin, in reanalysing these data, supported Wrigley et al. and reported a significant increase in F\&V consumption in switchers; however, only in those who already consumed more during the pre-intervention ${ }^{(29)}$. Moreover, according to both Cummins et al. and Gill and Rudkin, residents living close to the store benefited the most. A non-significant increase from 2.56 to 2.81 portions/d in F\&V consumption was revealed in respondents within a $750 \mathrm{~m}$ radius of the store using a straight-line distance approach ${ }^{(32,35)}$, while 0.7 portions/d increase (non-significant) was reported among those who lived in close proximity to the store and did not have a motor vehicle, using a road network measurement ${ }^{(29)}$. Focus group discussions post-intervention in Seacroft revealed that young respondents had negative attitudes about healthy eating, and in households with children that the children had a big influence on food purchasing and consumption patterns ${ }^{(39)}$. However, older switchers noted a positive influence on their eating habits due to the new store, while some participants learned about healthy eating only after the intervention ${ }^{(39)}$.

\section{Self-rated health and psychological health}

Cummins et al. reported an increased odds $(\mathrm{OR}=1.52$; $95 \%$ CI $0.77,2.99)$ of fair-to-poor self-rated health (adjusted for baseline and for confounders) in the intervention $v$. control groups, although this was not statistically significant ${ }^{(31,38)}$. As well, they reported non-significant improvements in psychological health in the intervention $v$. control groups (OR $=0.57 ; 95 \%$ CI $0 \cdot 29,1 \cdot 11)$. Nevertheless, switchers showed a significant change in psychological health compared with nonswitchers (OR $=0.24 ; 95 \%$ CI 0.09, 0.66).

\section{$B M I$}

Two studies measured BMI; neither of them found significant difference-in-differences through intention-to-treat analyses or on-treatment analyses ${ }^{(30,37)}$.

\section{Perceptions of food access}

Interestingly and importantly, two studies that assessed perceptions of food access revealed positive impacts. One intervention showed significantly greater differencein-differences for a variety of components related to 'perceived access to healthy food' among both the intervention $v$. comparison and regular users $v$. others in the intervention $\operatorname{area}^{(37)}$. Another intervention revealed significantly greater perceptions of food access (1.47; adjusted) among the intervention $v$. comparison groups ${ }^{(30)}$.

\section{Other outcomes}

Wang et al. found increases in walking among those who switched to the new store ${ }^{(33)}$, while the focus group discussions highlighted improvements in self-esteem among neighbourhood residents due to a new store in Leeds ${ }^{(39)}$. Dubowitz et al. also monitored the level of neighbourhood satisfaction for the Pittsburgh intervention and found a significant improvement $(11.10 \%)$ in the intervention $v$. comparison groups ${ }^{(37)}$.

\section{Discussion}

Health disparities arising due to unhealthy dietary patterns are becoming a serious public health issue ${ }^{(41,42)}$. Overcoming these serious health issues is critical. Practices of food procurement and eating are two of the most highly variable human activities with direct health consequences; therefore, they are also among the most valuable targets to direct preventive strategies ${ }^{(41)}$.

The present systematic review assessed the impact of opening new grocery stores in areas with previous low grocery store access on diet and selected health-related outcomes of neighbourhood residents. Review of eleven 
records of seven interventions revealed that new grocery store interventions have in general had an inconclusive influence on health-related outcomes in adults. Of the seven interventions, all reported $\mathrm{F} \& \mathrm{~V}$ consumption as a proxy for healthy eating behaviour while few studies examined self-reported health, psychological health, BMI, perceptions of food access and self-reported household food availability. Significant increases in F\&V consumption were detected in only one intervention among switchers who already consumed more F\&V during pre-intervention, or who lived near the new store. Conversely, one study reported significantly lower household F\&V availability, while another reported a non-significant decline in daily $\mathrm{F} \& \mathrm{~V}$ consumption in both intervention and comparison neighbourhoods. Further, one more intervention found that the intervention group was significantly more likely to consume unhealthy food. Among other healthrelated outcomes, there were significant improvements in perceived food access, neighbourhood satisfaction and poor psychological health. One intervention did not have any impact at all on healthy eating behaviour. In the two studies that measured BMI, they failed to detect any significant changes. It is surprising that only one study in the review reported food insecurity (although the intervention's impact on the food insecurity was not clearly stated) as poor geographic access to food contributes to food insecurity ${ }^{(33)}$ and this is the issue that the intervention was hoping to address.

The strength of evidence produced by these studies is generally weak, where the majority $(66.67 \%)$ of studies had 'weak' methodological quality and only $22.22 \%$ had 'strong' and $11.11 \%$ had a 'moderate' methodological quality. Although the quality of the majority of studies reviewed was weak according to the quality assessment tool used, they do, however, represent some of the betterquality evidence generated in an ethically possible manner, because the nature of these interventions is such that it is not possible to conduct randomized controlled trials. Therefore, while interpretations of the study results need to be made with caution, they provide the best possible results of natural experiments. It should be noted, however, that future research on interventions are encouraged to utilize better methods, such as longitudinal studies followed up for longer time periods, studies showing graded relationships and validated tools, to make evidence even stronger.

A noteworthy observation was that all of the interventions reviewed had occurred in areas designated as socioeconomically disadvantaged or low-income neighbourhoods. People living in these neighbourhoods are at high risk for poor diet due to poor healthy food access, abundance of unhealthy food exposure and poor public transit options ${ }^{(43,44)}$. Apart from poor healthy food access, many of these neighbourhoods also suffer from low basic public and private services, social exclusion and associated oppressions ${ }^{(45)}$. These accumulated deprived conditions contribute to major grocery store retailers locating further away, partly due to business and other regulatory policies or practices, or economic reasons ${ }^{(17)}$.

Food consumption behaviour is influenced by multiple factors ${ }^{(20)}$. Establishing a new grocery store alters community and consumer nutrition environments. This modified nutrition environment leaves the relationship between eating behaviour and individual factors to remain unchanged, making it hard to achieve any change in health behaviour by modifying only one component, i.e. environmental determinants. Some authors already identified this and acknowledged the importance of combined efforts to address healthy eating. For example, Wang et al. recognized the importance of combining traditional public health individual- and family-focused perspectives into these interventions if any effect is to be detected ${ }^{(33)}$. Likewise, independent associations between healthy food access and healthy eating are yet to be uncovered and understood $^{(46)}$.

When assessed, interventions changed individuals' perceived access to healthy food ${ }^{(30,37)}$. This observation could be claimed as a positive behaviour change step due to grocery store interventions towards reducing health inequalities by changing the dietary habits ${ }^{(47)}$. For instance, according to the transtheoretical model the core processes of change, which is described as individuals progressing through stages of change from precontemplation to maintenance and to termination, begins with a change in perception related to the behaviour change in question $^{(47)}$. In particular, change in perception towards healthy food access exemplifies implicit and explicit processes of change such as consciousness raising, social liberation and stimulus control ${ }^{(47)}$. Intervention cohorts had more opportunities/alternatives to practise healthy food habits while avoiding unhealthy food habits. This suggests that in the long term these interventions, if sustained, could lead to positive changes in food behaviour and ultimately to narrowing of health disparities.

Despite the fact that grocery stores promote healthy food, many also offer a variety of highly processed products high in sugar, salt and fat ${ }^{(34,36)}$. Further, exposure to a grocery store with a large variety of products may contribute to buying products that are not core food items, thereby overspending on non-essential items. In fact, focus group discussions by Wrigley et al. revealed that although the new store increased accessibility and convenience, some residents were concerned about 'temptation to overspend' when they used the new store ${ }^{(39)}$. Financial difficulties that may be associated with consuming a healthy diet, while trying to balance a tight budget for other essentials such as housing and transport, might offer a challenging task for low-income households. Spending a limited budget on transport could affect the amount of money that is spent on food and ultimately reflect as lower $\mathrm{F} \& \mathrm{~V}$ consumption contributing to poorer health. Focus groups, in fact, revealed that the new food 
store within walking distance saved them transport cost previously used for travelling to get groceries ${ }^{(39)}$.

In analysing the systematic review results, the context in which these interventions occur and that of their applicability should be considered. For example, retail food environments in Canada and the USA are dissimilar ${ }^{(48)}$; thus, the interventions which occurred in the USA might not completely be transferable to Canada. Five of the interventions reviewed from the USA were in locations where African-American populations were a majority $30,33,34,36,37)$. A study from the UK, reporting improvements in F\&V consumption, had a white majority ${ }^{(29,32,35,39)}$. Having a large minority ethnic group as participants might have skewed health-related outcomes reported, as it is widely known that low-income minority subgroups reportedly have poorer health outcomes such as obesity compared with the white majority in the USA ${ }^{(49)}$. Therefore, one could argue that not showing any significant impact in these studies might be due to the combined low socio-economic and racial/ethnic health disparities that already exist and that intervention impacts on other groups of the population might bear different results. According to intersectionality theory, multiple disadvantaged conditions might result in worse health outcomes than when each condition is taken singly ${ }^{(50)}$. As such, detection of the effects of food environment interventions might need examination of participants' many disadvantaged conditions all taken together.

The majority of studies reviewed used well-tested and standardized measurement tools ensuring high quality of data presented. Further, all studies investigated individual shopping behaviour where participants' primary grocery shopping details were examined, warranting that data were reported at the individual level and not at an ecological level. Moreover, all but one ${ }^{(33)}$ of the studies were prospective observational studies, which facilitated reducing potential recall bias. Additionally, all studies were published within the past 14 years, suggesting that the evidence produced is current and would be applicable to the present food environment discourse.

These studies have varied follow-up periods from 1-4 months up to 12 months, and numbers of participants ranging from seventy-eight to 1009. Study designs used were also very diverse and included one-time surveys with retrospective data collection ${ }^{(33)}$, uncontrolled before/after studies $^{(29,32,35)}$, before/after studies with different samples from the same population ${ }^{(34)}$, controlled pre-post quasiexperimental designs ${ }^{(30,31,37,38)}$ and a street-intercept survey $^{(36)}$. Differences in follow-up periods, sample sizes and study designs make the comparison of studies challenging.

Although the majority of interventions relied on detailed and well-established measures to assess outcomes, some studies used single-item questions ${ }^{(31)}$. Using brief instruments to assess outcomes such as F\&V consumption and diet has shown to be less effective in actually measuring what needs to be assessed compared with tools with more detailed questions ${ }^{(51)}$. Results produced would be more reliable if all studies used detailed and comprehensive measurement instruments.

Selecting areas with the highest level of deprivation might not be the best option to evaluate these interventions as healthy eating might be one out of many challenges these deprived populations face in everyday life. For instance, food price is one of the major limiting factors for low-income households when it comes to purchasing healthy food ${ }^{(52)}$. Further, healthy food costs more than less healthy options ${ }^{(53)}$ and literature indicates that price reductions and monetary incentives are interventions that might work for low-income populations ${ }^{(54)}$. Although food access is improved with grocery store interventions, the concomitant impact on food price might be limited. In fact, healthy food basket pricing in Flint, Michigan found that the price was significantly higher in a food desert than in the rest of the city ${ }^{(55)}$. The higher price was reduced after opening two grocery stores in the food desert but remained higher than in the remainder of the city on average $^{(55)}$. This might be leading to low-income residents not being able to change their diet due to their limited budgets. This assumption is supported by results showing that although neighbourhood residents have improved their perceptions of food access, they did not show any significant changes in F\&V consumption or BMI. In contrast, this could also be a function of BMI taking a longer time to change while individuals' perceived food access, self-esteem and neighbourhood satisfaction could change sooner. Further studies that incorporate several intervention components such as monetary incentives or price reductions for healthy food with new store interventions might provide balanced results.

Changes in eating behaviour and subsequent healthrelated outcomes might also take a longer time to change and show any detectable effects. Some authors highlight this limitation of food environment interventions, specifically Cummins et al. argued that significantly improved perceptions of food access among participants is a positive indication of better health in the long run ${ }^{(30)}$. Elbel et al. proposed that more than 1 year might be necessary for neighbourhood residents to change eating behaviour and subsequently to see any impact on health-related outcomes $^{(36)}$.

Further, these seven interventions took place in two countries. Outcomes of these studies should be interpreted in the context in which they occurred. For instance, the Seacroft intervention showed a significant impact on $\mathrm{F} \& \mathrm{~V}$ consumption among switchers. It was an initiative which had enormous government backing and targeted poor neighbourhoods specifically ${ }^{(45)}$. It was an intervention not only to increase food access, but also to combat social exclusion ('Seacroft green' Centre) and had the intention to provide unemployed local residents with employment opportunities ${ }^{(45)}$. In contrast, the grocery store opened in Flint, Michigan was a privately invested 
venture, was closed after 1 year in business and had no government support ${ }^{(34)}$. Complex and context-specific interventions may have many prominent or subtle effects, with acceptability of interventions by residents and subsequent change in behaviour influenced by many known and unknown factors. For instance, if a new grocery store was opened in a disadvantaged, predominantly low-income neighbourhood, and if the community had the understanding that the store was established primarily for low-income residents, some people might be reluctant to shop at the new store. Unknown factors such as the above are difficult to capture and their effects on health-related outcomes might be considerable. Future retail food environment interventions should take these subtle effects into consideration when assessing intervention impact.

\section{Limitations}

While the body of literature exploring the food environment is large, studies evaluating new grocery store interventions are very few to date. We limited our search to only peer-reviewed literature published in English language after 1995 in selected but comprehensive electronic databases. Therefore, it is possible that relevant studies, for instance those published as non-peer reviewed reports or only in less comprehensive electronic databases, were missed. Further, included studies had used dissimilar methodologies which made comparisons challenging.

\section{Conclusion}

As discussed, approaches which address single aspects of healthy eating (such as improved access to retail food stores) do not seem to enhance diet and other selected health-related outcomes such as self-rated health, psychological health and BMI in an effective manner over short durations. These interventions might prove successful and result in intended effects in the longer term, yet we do not have enough evidence to say whether this is the case. Conversely, as complex and multifaceted dietary behaviours and resulting health-related outcomes are, interventions that aim to address these problems should also have multidimensional and multipronged approaches if any effect is to be seen. Presently the field of retail food environment interventions is developing and the complex linking pathways that connect these interventions to diet and health are yet to be elucidated. Further evidence is needed in the form of high-quality research to uncover these complex associations, as well as interventions in different communities and contexts with longer follow-up periods to inform policy decisions and recommendations.

\section{Acknowledgements}

Acknowledgements: The authors would like to thank Lukas Miller, the liaison librarian for Community Health and
Epidemiology in the Leslie and Irene Dube Health Sciences library at the University of Saskatchewan, for his assistance during the search strategy development. They would also like to thank Tracy Ridalls, Joel Heitmar, Melissa Gan and Mike Chouinard for their contribution in the initial title screening of articles; and Dr Sharon Kirkpatrick, Assistant Professor, School of Public Health and Health Systems, University of Waterloo, for her reviews. Financial support: Funding for this study was from a grant from the Canadian Institutes of Health Research (\#127084). A.M.H.A. was supported through CREATE/ITraP (Collaborative Research and Training Experience/Integrated Training Program in Infectious Disease, Food Safety and Public Policy) during the study period. The funders had no role in the design, analysis or writing of this article. Conflict of interest: None. Authorship: This systematic review was conceived and designed by N.M. and R.E.-S. A.M.H.A. conducted the search, extracted data and composed the manuscript. All authors contributed to the quality assessment of individual studies, interpretation of the findings and preparation of the manuscript. Ethics of buman subject participation: Not applicable.

\section{Supplementary material}

To view supplementary material for this article, please visit https://doi.org/10.1017/S1368980017000933

\section{References}

1. Fiechtner L, Kleinman K, Melly SJ et al. (2016) Effects of proximity to supermarkets on a randomized trial studying interventions for obesity. Am J Public Health 106, 557-562.

2. Ginn A, Majumdar A, Carr M et al. (2016) Mapping access to community-developed healthy food baskets including cost and availability. Health Educ J 75, 911-924.

3. Powell LM, Kumanyika SK, Isgor Z et al. (2016) Price promotions for food and beverage products in a nationwide sample of food stores. Prev Med 86, 106-113.

4. Goryakin Y, Rocco L, Suhrcke M et al. (2015) Individual and community-level determinants of fruit and vegetable consumption in nine former Soviet Union countries. Public Health Nutr 18, 2825-2835.

5. Wang MC, Cubbin C, Ahn D et al. (2008) Changes in neighbourhood food store environment, food behaviour and body mass index, 1981-1990. Public Health Nutr 11, 963-970.

6. Larson NI, Story MT \& Nelson MC (2009) Neighborhood environments: disparities in access to healthy foods in the US. Am J Prev Med 36, 74-81.e10.

7. Auchincloss AH, Mujahid MS, Shen M et al. (2013) Neighborhood health-promoting resources and obesity risk (the multi-ethnic study of atherosclerosis). Obesity (Silver Spring) 21, 621-628.

8. Lamichhane AP, Warren J, Puett R et al. (2013) Spatial patterning of supermarkets and fast food outlets with respect to neighborhood characteristics. Health Place 23, $157-164$.

9. Trapp GS, Hickling S, Christian HE et al. (2015) Individual, social, and environmental correlates of healthy and unhealthy eating. Health Educ Behav 42, 759-768. 
10. Polsky JY, Moineddin R, Glazier RH et al. (2014) Foodscapes of southern Ontario: neighbourhood deprivation and access to healthy and unhealthy food retail. Can J Public Health 105, E369.

11. Maguire E, Burgoine T \& Monsivais P (2015) Area deprivation and the food environment over time: a repeated cross-sectional study on fast food outlet density and supermarket presence in Norfolk, UK, 1990-2008. Health Place 29, 1 Suppl., 132-134.

12. Beaulac J, Kristjansson E \& Cummins S (2009) A systematic review of food deserts, 1966-2007. Prev Chronic Dis 6, A105.

13. Ghosh-Dastidar B, Cohen D, Hunter G et al. (2014) Distance to store, food prices, and obesity in urban food deserts. $A m J$ Prev Med 47, 587-595.

14. McInerney M, Csizmadi I, Friedenreich CM et al. (2016) Associations between the neighbourhood food environment, neighbourhood socioeconomic status, and diet quality: an observational study. BMC Public Health 16, 984.

15. Whelan A, Wrigley N, Warm D et al. (2002) Life in a 'food desert'. Urban Stud 39, 2083-2100.

16. Walker RE, Keane CR \& Burke JG (2010) Disparities and access to healthy food in the United States: a review of food deserts literature. Health Place 16, 876-884.

17. Zhang M \& Ghosh D (2016) Spatial supermarket redlining and neighborhood vulnerability: a case study of Hartford, Connecticut. Trans GIS 20, 79-100.

18. Franco M, Roux AVD, Glass TA et al. (2008) Neighborhood characteristics and availability of healthy foods in Baltimore. Am J Prev Med 35, 561-567.

19. Giang T, Karpyn A, Laurison HB et al. (2008) Closing the grocery gap in underserved communities: the creation of the Pennsylvania Fresh Food Financing Initiative. J Public Health Manag Pract 14, 272-279.

20. Glanz K, Sallis JF, Saelens BE et al. (2005) Healthy nutrition environments: concepts and measures. Am J Health Promot 19, 330-333.

21. Story M, Kaphingst KM, Robinson-O'Brien R et al. (2008) Creating healthy food and eating environments: policy and environmental approaches. Annu Rev Public Health 29, 253-272.

22. Gittelsohn J (2012) Interventions in small food stores to change the food environment, improve diet, and reduce risk of chronic disease. Prev Chronic Dis 9, E59.

23. Escaron AL, Meinen AM, Nitzke SA et al. (2013) Supermarket and grocery store-based interventions to promote healthful food choices and eating practices: a systematic review. Prev Chronic Dis 10, E50.

24. Thomas B, Ciliska D, Dobbins M et al. (2004) A process for systematically reviewing the literature: providing the research evidence for public health nursing interventions. Worldviews Evid Based Nurs 1, 176-184.

25. Effective Public Health Practice Project (2009) Quality Assessment Tool for Quantitative Studies. http://www. ephpp.ca/tools.html (accessed March 2016).

26. National Collaborating Centre for Methods and Tools (2016) Quality Assessment Tool for Quantitative Studies. http:// www.nccmt.ca/registry/view/eng/14.html (accessed March 2016).

27. Craig P, Cooper C, Gunnell D et al. (2012) Using natural experiments to evaluate population health interventions: new Medical Research Council guidance. J Epidemiol Community Health 66, 1182-1186.

28. Bonell CP, Hargreaves J, Cousens S et al. (2011) Alternatives to randomisation in the evaluation of public health interventions: design challenges and solutions. J Epidemiol Community Health 65, 582-587.

29. Gill L \& Rudkin S (2014) Deconstructing supermarket intervention effects on fruit and vegetable consumption in areas of limited retail access: evidence from the Seacroft Study. Environ Plann A 46, 649-665.
30. Cummins S, Flint E \& Matthews SA (2014) New neighborhood grocery store increased awareness of food access but did not alter dietary habits or obesity. Health Aff (Millwood) 33, 283-291.

31. Cummins S, Petticrew M, Higgins C et al. (2005) Large scale food retailing as an intervention for diet and health: quasi-experimental evaluation of a natural experiment. J Epidemiol Community Health 59, 1035-1040.

32. Wrigley N, Warm D \& Margetts B (2003) Deprivation, diet, and food-retail access: findings from the Leeds 'food deserts' study. Environ Plann A 35, 151-188.

33. Wang MC, MacLeod KE, Steadman C et al. (2007) Is the opening of a neighborhood full-service grocery store followed by a change in the food behavior of residents? J Hunger Environ Nutr 2, 3-18.

34. Sadler RC, Gilliland JA \& Arku G (2013) A food retail-based intervention on food security and consumption. Int $J$ Environ Res Public Health 10, 3325-3346.

35. Wrigley N, Warm D, Margetts B et al. (2002) Assessing the impact of improved retail access on diet in a 'food desert': a preliminary report. Urban Stud 39, 2061-2082.

36. Elbel B, Moran A, Dixon LB et al. (2015) Assessment of a government-subsidized supermarket in a high-need area on household food availability and children's dietary intakes. Public Health Nutr 18, 2881-2890.

37. Dubowitz T, Ghosh-Dastidar M, Cohen DA et al. (2015) Diet and perceptions change with supermarket introduction in a food desert, but not because of supermarket use. Health Aff (Millwood) 34, 1858-1868.

38. Cummins S, Findlay A, Higgins C et al. (2008) Reducing inequalities in health and diet: findings from a study on the impact of a food retail development. Environ Plann A $\mathbf{4 0}$, 402-422.

39. Wrigley N, Warm D, Margetts B et al. (2004) The Leeds 'food deserts' intervention study: what the focus groups reveal. Int J Retail Distrib Manag 32, 123-136.

40. Ten Have TR, Normand SLT, Marcus SM et al. (2008) Intentto-treat vs. non-intent-to-treat analyses under treatment nonadherence in mental health randomized trials. Psychiatr Ann 38, 772-783.

41. World Health Organization (2003) Diet, Nutrition and the Prevention of Chronic Diseases. Report of a Joint WHO/FAO Expert Consultation. WHO Technical Report Series no. 916. Geneva: WHO.

42. Drewnowski A \& Darmon N (2005) The economics of obesity: dietary energy density and energy cost. Am J Clin Nutr 82, 1 Suppl., 265S-273S.

43. Cushon J, Creighton T, Kershaw T et al. (2013) Deprivation and food access and balance in Saskatoon, Saskatchewan. Chronic Dis Inj Can 33, 146-159.

44. Powell LM, Slater S, Mirtcheva D et al. (2007) Food store availability and neighborhood characteristics in the United States. Prev Med 44, 189-195.

45. Wrigley N, Guy C \& Lowe M (2002) Urban regeneration, social inclusion and large store development: the Seacroft development in context. Urban Stud 39, 2101-2114.

46. Cummins S, Petticrew M \& Sparks L (2005) Large scale food retail interventions and diet: improving retail provision alone may not have a substantial impact on diet (Editorial). BMJ 330, 683-684.

47. Prochaska J, Redding C \& Evers K (2008) The transtheoretical model and stages of change. In Health Behaviour and Health Education: Theory, Research, and Practice, 4th ed. pp. 97-121 [K Glanz, B Rimer and K Viswanath, editors]. San Francisco, CA: Jossey-Bass.

48. Minaker LM, Shuh A, Olstad DL et al. (2016) Retail food environments research in Canada: a scoping review. Can J Public Health 107, 4-13.

49. Wang Y \& Beydoun MA (2007) The obesity epidemic in the United States - gender, age, socioeconomic, racial/ethnic, 
and geographic characteristics: a systematic review and meta-regression analysis. Epidemiol Rev 29, 6-28.

50. Viruell-Fuentes EA, Miranda PY \& Abdulrahim S (2012) More than culture: structural racism, intersectionality theory, and immigrant health. Soc Sci Med 75, 2099-2106.

51. Kirkpatrick SI, Reedy J, Butler EN et al. (2014) Dietary assessment in food environment research: a systematic review. Am J Prev Med 46, 94-102.

52. French SA (2003) Pricing effects on food choices. J Nutr 133, issue 3, 841S-843S.

53. Cavanaugh E, Mallya G, Brensinger C et al. (2013) Nutrition environments in corner stores in Philadelphia. Prev Med 56, 149-151.
54. Powell LM, Chriqui JF, Khan T et al. (2013) Assessing the potential effectiveness of food and beverage taxes and subsidies for improving public health: a systematic review of prices, demand and body weight outcomes. Obes Rev 14, 110-128.

55. Sadler RC, Gilliland JA \& Arku G (2013) Community development and the influence of new food retail sources on the price and availability of nutritious food. J Urban Aff 35, 471-491.

56. Government of Canada (2016) Supermarkets and Other Grocery (except Convenience) Stores (NAICS 44511): Definition. https://strategis.ic.gc.ca/app/scr/sbms/sbb/cis/definition.html? code $=44511$ \&lang=eng (accessed August 2016). 